International Journal of Computer Networks \& Communications (IJCNC) Vol.4, No.1, January 2012

\title{
Demonstration and Performance Analysis OF ROF BASED OFDM-PON SYSTEM FOR NEXT- GENERATION FABER OPTIC COMMUNICATION
}

\author{
Nadia Nowshin,Member, IEEE, A K M Arifuzzman,Member, IEEE, Mohammed \\ Tarique,Senior Member, IEEE
}

\begin{abstract}
In this paper through the basic components of fiber optic communication, a novel transmission system for seamless integration of ROF (Radio Over Fiber) with centralized lightwave OFDM-PON based on an integrated external modulator is demonstrated. Here we have investigated the transmission performance of a modulation based on a proposed technique of Orthogonal Frequency Division Multiplexing (OFDM) for Next-Generation Passive Optical Network (NG-PON). The signal is generated by direct modulation of cost-effective and low bandwidth commercially available CW Lasers of $193.1 \mathrm{THz}$. The Downstream OFDM-PON transmission (5 Gbits/sec total, $2.5 \mathrm{Gbits} / \mathrm{sec}$ for each user) are experimentally demonstrated over a $50 \mathrm{~km}$ standard single mode fiber and additionally simulated through 1:2 splitter. And finally experimental results are analyzed based on optical signal spectrum in time-domain and compared with numerical results for different QAM (Quadrature Amplitude Modulation) and PSK (Phase Shift Keying) modulation schemes to demarcate concluding statements.
\end{abstract}

\section{KEYWORDS}

Orthogonal Frequency Division Multiplexing (OFDM), Passive Optical Network (PON), Radio- OverFiber (ROF), Optical Line Terminal (OLT), Optical Network Unit (ONU).

\section{INTRODUCTION}

In the era of $21^{\text {st }}$ century rapid communication network, high application services like peer-topeer (P2P) file sharing, video on demand services, High Definition Multimedia Television (HDTV), 3DTV are considered to be the most promising services, which requires a significant increase in bandwidth. And passive optical network (PON) is a promising solution for such communicative networks. It can provide different customers with simultaneous delivery of multiple-services over a common network [1-2]. But higher bandwidth requirement also increases the cost of transmission. So, the cost reduction in future PON systems will be the key challenge for operators' deployment.

PON uses multicarrier modulation like orthogonal frequency division multiplexing (OFDM), which provides an opportunity of having an increased in bandwidth together with an affordable cost and this idea has recently become a suitable topic for many research works [3-4]. Due to its less Inter Symbol Interference (ISI), computational complexity and more robustness as compared to other multiplexing schemesand Orthogonal Frequency Division Multiplexing (OFDM) has been extensivelyused in wireless communication. OFDM dominated in wireless broadcast system such as Wi-Fi and WiMAX because of its robustness to multipath fading and high sub-carrier

DOI : $10.5121 /$ ijcnc.2012.4114 
density through the digital FFT and IFFT [5]. As the underlying optical backbone for example PON become extensively deployed and recently cost-effective implementation of high-speed PON is of great interest [6-8]. And OFDM provided the better spectrum utilization and high transmission rate using low-cost optical components by M-ary modulation on its subcarriers, such as Phase-Shift-Keying (PSK) or Quadrature Amplitude Modulation (QAM) [3]. Besides that OFDMA (Orthogonal Frequency Division Multiple Access), a multi-user version of OFDM, is capable of assigning subsets of sub-carriers to different users dynamically. Thus the total system bandwidth resources can be shared by all users [9].Another promising alternative pathway toward ultrahigh capacity optical network is Coherent Optical Orthogonal Frequency Division Multiplexing (CO-OFDM). Most recently Coherent Optical OFDM (CO-OFDM) [10] and DirectDetection Optical OFDM (DDO-OFDM) [11-14] has been proposed and investigated to offer many advantages for future high speed fiber transmission system.

The freshness of this paper lies in the fact that it demonstrates OFDM-PON architecture for downstream through M-ary QAM and M-aryPSK. Here we also analyzed the transmitted pulse spectrum and the received pulse spectrum at each ONU of the network with detailed parameters to find out the dispersion for different modulation technique.

This paper is organized as follows: Section II consists of the technical principle which is again segmented into OFDM technique implementation with QAM/PSK, Explanation of our proposed Passive optical Network (PON) and OFDM through PON. Then Section III describes the Experimental setup. After that the experimental parametersare extractedin Section IV. Section V states the simulated results and correspond discussions and finally Section VI wraps up with the Conclusion.

\section{TECHNICAL PRINCIPLE}

\section{A. OFDM WITH QAM / PSK}

Inpractice, OFDM systems are implemented using a combination of Fast Fourier Transform (FFT) and Inverse Fast Fourier Transform (IFFT) blocks as shown in Figure 1, that are mathematically equivalent versions of the DFT and IDFT respectively, but more efficient to implement. 


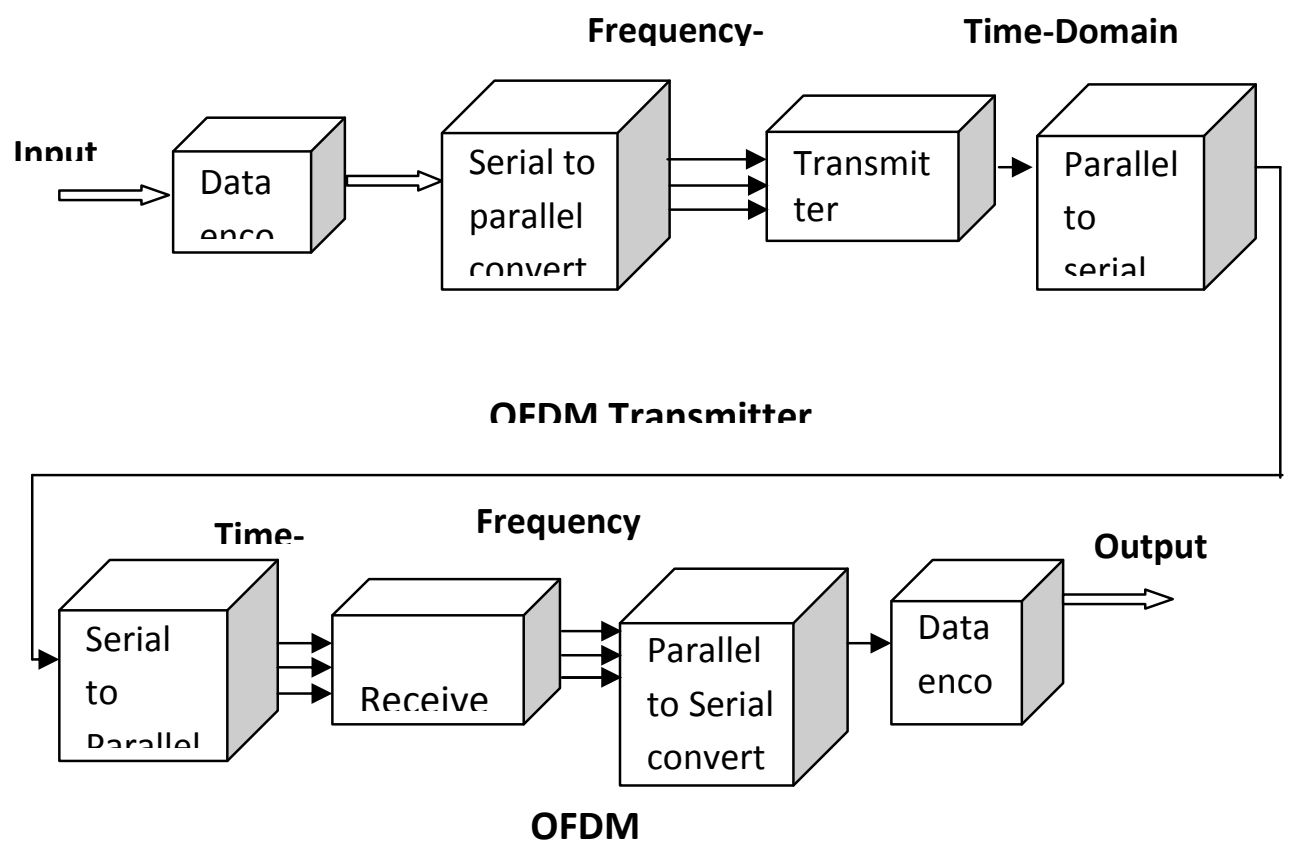

Figure 1. Block diagram of a simple OFDM system

An OFDM system considers the source symbols at the transmitter side(e.g., QAMorPSK symbols that can be presented in a single carrier system) to be in the frequency-domain. These symbols are used as inputs to an IFFT block that transfers the signal into time-domain. If the number of subcarriers used in the system is $\mathrm{N}$ then the IFFT takes in $\mathrm{N}$ symbols as an input at a time with a time period $\mathrm{T}$ second. The basic functions for an IFFT are $\mathrm{N}$ orthogonal sinusoids. These sinusoids each have a different frequency. Eachof those input symbol behaves like a complex value for the corresponding sinusoidal basis function. And the output of the IFFT is the summation of all $\mathrm{N}$ sinusoids. After that the output of the IFFT block passed through a digital-toanalog (D/A) converter and employed to modulate the carrier which results in the ODFM signal. And this process can be expected as an easy way to modulate data onto $\mathrm{N}$ orthogonal subcarriers. And at the receiver, an FFT block is used to bring the received signalit back into the frequency domain. The received signal is initially down converted to the baseband signal and then passed through an analog-to-digital (A/D) converter in order to get the digitized values. The digital values is again portioned into blocks of length $\mathrm{N}$ and demodulated block by block by the FFT.Thus the original symbols are generated that were sent as inputs to the transmitter IFFT block. When the FFT output samplesare plotted in the complex plane, they will from a constellation (such as QPSK, 16-QAM, 32-QAM etc.). The block diagram in Figure 1 illustrates the switch between frequency-domain and time-domain in an OFDM system.

\section{B. Passive Optical Network (PON)}

Fiber optics propagates light signals to transmit data or information. There are two important types of systems that make fiber optic broadband connections possible. These are active optical 
networks and passive optical networks. Each of the two networkssplits data/information and route them to the appropriate place, and each of the two networkshas strengths and weaknesses as compared to the other.

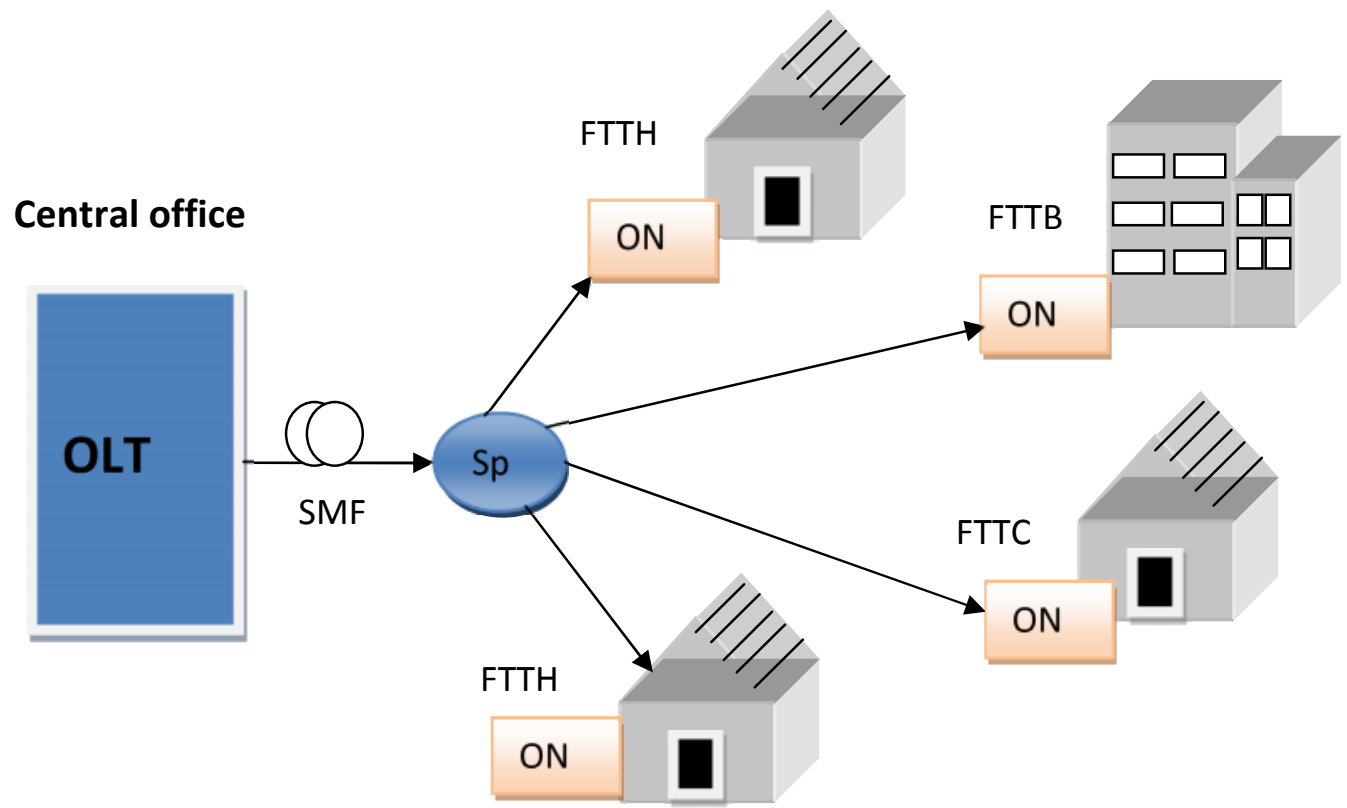

OLT-Optical Line Terminal, ONU-Optical Network Unit, SMF- Single Mode Fiber, Sp-

Figure 2. Block diagram of a simple PON (Passive Optical Network)

An active optical system normally requires switching equipment that runs through electricity, such as, power combiners, multiplexers, demultiplexers, electrical decoders, routers or switch aggregators, to accomplishsuccessful signal distribution to specific end user. There are a number of ways to perform the transmission and reception of information through switching. And in case of anactive optical system, eachend user may have a committed fiber running to his or her house. Whereas a passive optical network, on the other hand, does not requireswitching components running through electricity and instead of that they uses optical splitters or forks to distribute and accumulate optical signals when they pass through the network. A passive optical network uses fiber optic equipment for certain part of the network that's because it has been named as passive optical network. And another benefit of PON is that it uses electrically powered equipment only at the source and destination ends and can serve most probably upto 32 end users.

PON is a system that brings fiber optic cabling and signals to all or most of the way to the end user. Depending on where the PON terminates, the system can be described as FTTC (fiber-tothe-curb), FTTB (fiber-to-the-building), or FTTH (fiber-to-the-home).

Passive optical networks, or PONs, have some distinct advantages. They're efficient, in that each fiber optic strand can serve up to 32 users. PON has a low building cost relative to active optical networks along with lower maintenance costs. Because there are few moving or electrical parts, there's simply less that can go wrong in a PON. 
A PON (Figure 2) consists of an Optical Line Termination (OLT) at the communication company's office, a number of end user lumps named asOptical Network Units (ONUs) and the combiners, fibers and splitters between them are referred to as the Optical Distribution Network (ODN).An ONU is a device or portionof the network that ends up the PON and provides customer service interfaces to the user. Some ONUs implements a separate subscriber unit to provide services such as telephony, Ethernet data, or video. The OLT provides the interface between the PON and the service providers network services which typically includes Internet Protocol (IP) traffic over gigabit/s, $10 \mathrm{Gbit} / \mathrm{s}$, or $100 \mathrm{Mbit} / \mathrm{s}$ Ethernet, standard Time Division Multiplexed (TDM) interfaces such as SONET or Synchronous Digital Hierarchy (SDH)and Asynchronous Transfer Mode (ATM) User-network interface (UNI) at 155-622 Mbit/s etc. And the ONU that terminates the PON presents the native service interfaces to the user. These services comprisedynamically allocated bandwidth based plain telephone voice traffic/service, data traffic, voice traffic over internet protocol, video on demand, IP telephony services and/or telemetry (TTL, ECL, RS530, etc.).

Thus as a whole we can say that PON is a shared and distributed communication network, where the OLT collects all the voice/data traffic form ONUs and transmits them as a single stream of downstream traffic through the communication medium (fiber). But the impressive fact is that each ONU only retrieves the content of those packets that were addressed to it. Encryption and decryption is used to ensure the security of the system by precluding eavesdropping on downstream traffic.And the word "passive" simply designates the fact that once the signal startsmoving through the network there is no power requirements or active electronic part requirement in that portion of the network.

\section{OFDM with PON}

Point-to-multipoint OFDM based passive optical network (PON) is expected to play a leading role in next-generation access. It offers bandwidth flexibility not only in between users but also between applications (Figure 3) which include mix of digital, analog, circuit and packet-switched, legacy and emerging applications. 




Figure 3. OFDM based PON system

In OFDM-PON system sub-carriers become transparent pipes for delivery of arbitrary signals like Ethernet, RF,T1/E1, mobile backhaul, VPN,IPTV, etc. For this purpose bandwidth is dynamically assigned to different services or different users are assigned different OFDM subcarrier within one OFDM band of total N subcarriers.

\section{EXPERIMENTAL SETUP}

Our recommended OFDM-PON architecturebased on the point-to-multipoint (PMP) topology is illustrated in Figure 4(a) and 4(b). The topology consists of the Optical Line Terminal (OLT) 
situated at the Central Office (CO) and several Optical Network Units (ONUs) located at some particular distant location. Here the OLT comprises the fundamental blocks of RF OFDM transmitter and a RF-to-Optical(RTO) up-converter.And after passing through the optical link each ONU occupies an optical-to-RF (OTR) down-converter and a RF OFDM receiver. Here the subcarrier mapping enables spectrum division for different terminals and is essential for OFDM. Basically, the overall PON downstream bandwidth in baseband is $2.5 \mathrm{GHz}$ generated by digital IQ modulation is divided into several groups of orthogonal subcarriers.Dynamic allocation of subcarriers between ONUs is conducted intelligently by OLT. The OFDM block in scenario 1 of Figure 4 (a) has a FFT size of 64 and from which 52 subcarriers are used for data transmission.

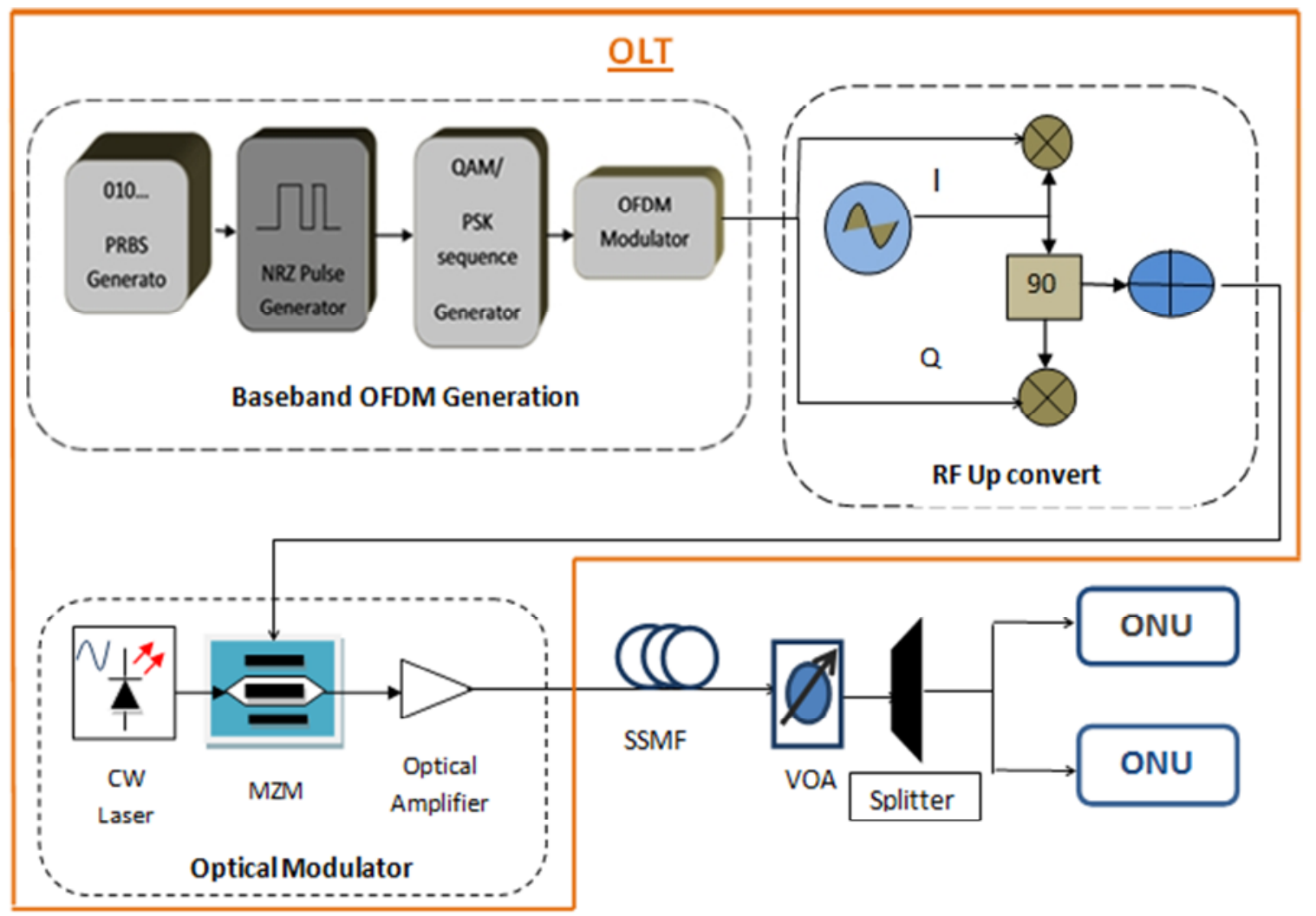

\section{Scenario 1-VOA- Voltage Optical Attenuator, ONU-Optical Network Unit}

Figure 4 (a).Proposed PMPPONArchitecture (for scenario 1) 
International Journal of Computer Networks \& Communications (IJCNC) Vol.4, No.1, January 2012

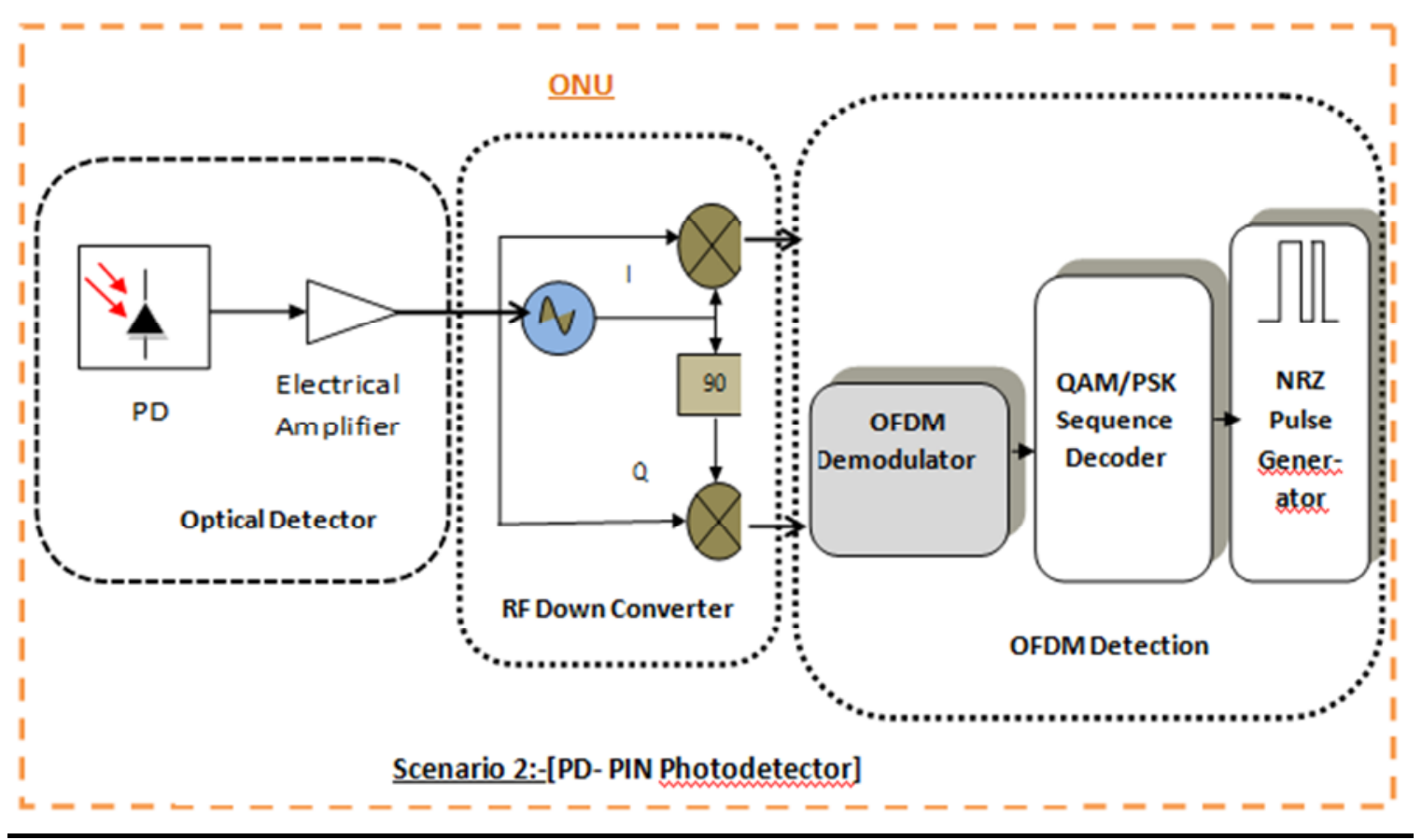

Figure 4 (b).Proposed PMPPONArchitecture (for scenario 2)

In the RF OFDM transmitter, the input digital data are first converted from serial to parallel block of bits consisting of information symbol where each symbol comprise multiple bits of Marycoding. And, in our proposed model we usedboth M-aryQAM and M-aryPSK for constellation. The time domain OFDM signal is obtained through Inverse Fast Fourier Transform (IFFT) and a guard interval is inserted to avoid channel dispersion. The baseband OFDM signal can be up-converted to a RF passband through a RF IQ mixer. The subsequent RTO up-converter transforms the baseband signal to the optical domain using an optical IQ modulator comprising a Mach- Zehnder-modulator (MZM) with a 90 degree phase offset. Then finally the optical signal from the OLT is transmitted through a $50 \mathrm{~km}$ standard single mode fiber (SSMF) together with a 10-db optical attenuator (OA) and 1:2 optical splitter. The fiber used in this model is SMF-28 fiber with $17 \mathrm{ps} / \mathrm{nm} / \mathrm{km}$ dispersion and an insertion loss of $0.2 \mathrm{~dB} / \mathrm{km}$ at $1550 \mathrm{~nm}$.

At the receiving end the optical signal travelling through the SSMF is converted back to RF OFDM signal by the OTR down-converter (scenario 2, Figure 4(b)). To maintain the received power is maintained between $-6 \mathrm{dBm}$ and $-19 \mathrm{dBm}$ by a VOA (Voltage Optical Attenuator), accounting a 4-5 dB from $50 \mathrm{~km}$ fiber and 9 $22 \mathrm{~dB}$ attenuator loss. The received RF signal is detected by a PIN photodetector which converts the optical signal to an electrical one. Besides the PIN photodetector the ONU also contains a digital I-Q demux, followed by an FFT and a channel estimation/equalization.

\section{ExPERIMEnTal PARAMETER EXTraction}

For Corning SMF-28 fiber, 
If the operating wavelength $=1550 \mathrm{~nm}$, then the attenuation $(A)$ at $1550 \mathrm{~nm}$ is $=0.19 \mathrm{db} / \mathrm{km}$, Transmitter output power $\left(P_{T}\right)=0 \mathrm{dBm}$, Total coupling loss $\left(L_{C}\right)=2 \times 0.5=1 \mathrm{~dB}$, Additional known Loss $\left(L_{A}\right)=0 \mathrm{~dB}$, System margin, $(M)=6 \mathrm{~dB}$ and Receiver sensitivity $\left(S_{R}\right)=-$ $30 \mathrm{dBm}$.

So, Power budget $=P_{T}-S_{R}=0 \mathrm{dBm}-(-30) \mathrm{dBm}=30 \mathrm{dBm}$.

Thus the maximum allowable fiber length $=\frac{(30-7) \mathrm{dB}}{0.19 \mathrm{~dB}^{\prime} \mathrm{km}}=121 \mathrm{~km}$.

As for the proposed model bit rate $(\mathrm{R})=2.5 \mathrm{Gbits} / \mathrm{sec}$ then the maximum allowable chromatic dispersion $\left(\Delta \mathrm{t}_{\max }\right)=\frac{1}{4 \mathrm{R}}=\frac{1}{4 \times 2.5 \times 10^{9}}-10^{-10} \mathrm{sec}=100 \mathrm{ps}$.

Fiber dispersion co-efficient $\mathrm{D}(\lambda)=\frac{S_{0}}{4}\left(\lambda-\frac{\lambda_{0}{ }^{4}}{\lambda^{3}}\right)=\frac{0.09}{4}\left\{1550-\frac{(1312)^{4}}{(1550)^{3}}\right\} \approx 17 \mathrm{ps} / \mathrm{nm}-\mathrm{km}$,

, where zero dispersion slope $\left(S_{0}\right)=0.09 \mathrm{ps} / \mathrm{nm}^{2}$, zero dispersion wavelength $\left(\lambda_{0}\right)=1312 \mathrm{~nm}$.

The RMS width of the transmitted pulse is $\mathrm{T}_{\mathrm{in}}=\frac{\mathrm{T}_{\mathrm{FWHM}(\mathrm{trans})}}{1.665} \mathrm{ps}(1)$

And the RMS width of the received pulse at each ONU is $\mathrm{T}_{\text {out }}=\frac{\mathrm{T}_{\mathrm{FWHM}} \text { (receive) }}{1.665} \mathrm{ps}(2)$

, where $\mathrm{T}_{\mathrm{FWHM}}$ is the FWHM width of the transmitted/received pulse.

And the RMS spectral width of the transmitted pulse or optical pulse,

$$
(\Delta \lambda)=\frac{\lambda^{2} \sqrt{1+\mathrm{C}^{2}}}{2 \pi c \mathrm{~T}_{\mathrm{in}}{ }^{2}}(3)
$$

, where chirp factor $(C)=-6$, wavelength $(\lambda)=1550 \mathrm{~nm}$, speed of light $(\mathrm{c})=3 \times 10^{8} \mathrm{~m} / \mathrm{s}$. So, the RMS width of the fiber impulse response

$$
\left(\mathrm{T}_{\mathrm{F}}\right)=\mathrm{L} \cdot \mathrm{D}(\lambda) \cdot \Delta \lambda(4)
$$

Thus the RMS width of the pulse at the far end of the optical fiber in each ONU is given by

$$
\mathrm{T}_{\text {out }}=\sqrt{\mathrm{T}_{\mathrm{in}}^{2}+\mathrm{T}_{\mathrm{F}}^{2}}(5)
$$

\section{RESULT AND DISCUSSION}

In this paper a software (Optisystem 10) based simulation is conducted to study the impact of different modulation schemes (M-ary PSK and M-ary QAM) on the downstream transmission (from OLT to different ONUs) performance of the proposed OFDM PON system. Total 52 subcarriers are used to create the OFDM signal. And the coefficient of each subcarrier will take complex values to carry M-ary modulations such QPSK or 16-PSK or 256-QAM. 

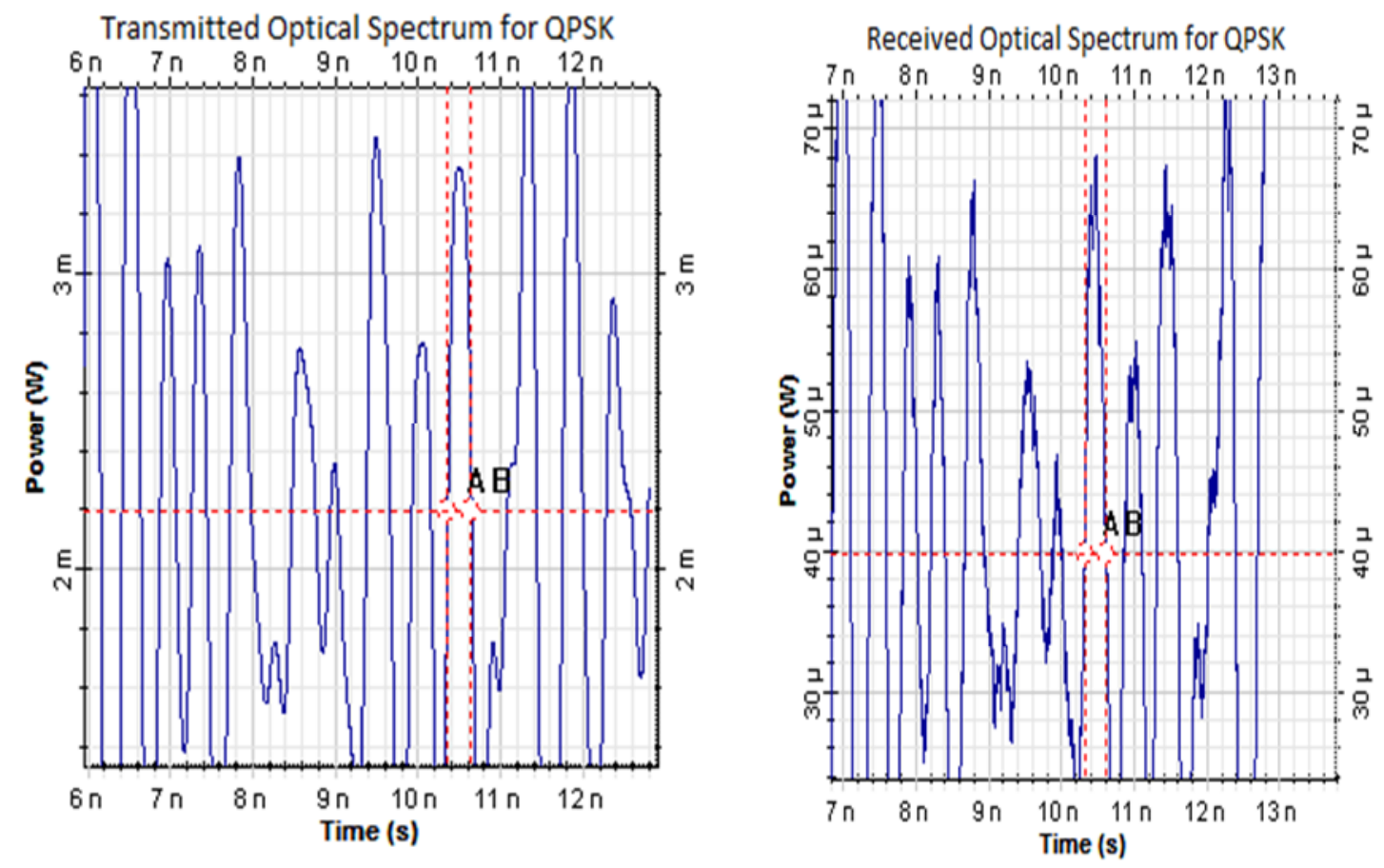

Figure 5. Transmitted and Received Optical Spectrum for QPSK.

From the transmitted and received optical spectra for QPSK (Figure 5) we can see that the FWHM width of the transmitted pulse (difference between point $\mathrm{A}$ and $\mathrm{B}$ ) is $\mathrm{T}_{\mathrm{FWHM}(\operatorname{trans})}=0.22$ $\mathrm{ns}=220 \mathrm{ps}$ and FWHM width of the received pulse is $\mathrm{T}_{\mathrm{FWHM}}$ (receive) $=0.25 \mathrm{~ns}=250 \mathrm{ps}$. So, from (eq.1) the RMS width of the transmitted pulse is $\mathrm{T}_{\mathrm{in}}=\frac{\mathrm{T}_{\mathrm{FWHM}} \text { (trans) }}{1.665} \mathrm{ps}=\frac{220}{1.665} \mathrm{ps} \approx 132 \mathrm{ps}$. And from (eq.2) the RMS width of the received pulse is $\mathrm{T}_{\text {out }}=\frac{\mathrm{T}_{\mathrm{FWHM}(\text { receive) }}}{1.665} \mathrm{ps}=\frac{250}{1.665} \mathrm{ps} \approx 150 \mathrm{ps}$. Now from eq. 3 the RMS spectral width of the transmitted optical pulse $(\Delta \lambda)=\frac{\lambda^{2} \sqrt{1+\mathrm{C}^{2}}}{2 \pi \mathrm{c} \mathrm{T}_{\text {in }}}=0.059$ $\mathrm{nm}$. So, the RMS width of the fiber impulse response $\left(\mathrm{T}_{\mathrm{F}}\right)=\mathrm{L} . \mathrm{D}(\lambda) . \Delta \lambda=(50 \mathrm{~km}) .(17 \mathrm{ps} / \mathrm{nm}-$ $\mathrm{km}) .(0.059 \mathrm{~nm})=50.15 \mathrm{ps}$. Thus the RMS width of the pulse at the far end of the optical fiber is $\mathrm{T}_{\mathrm{out}}=\sqrt{\mathrm{T}_{\mathrm{in}}{ }^{2}+\mathrm{T}_{\mathrm{F}}^{2}}=\sqrt{(132)^{2}+(50.15)^{2}}=138 \mathrm{ps}$, which is nearly equal to the simulated value (150 ps). 

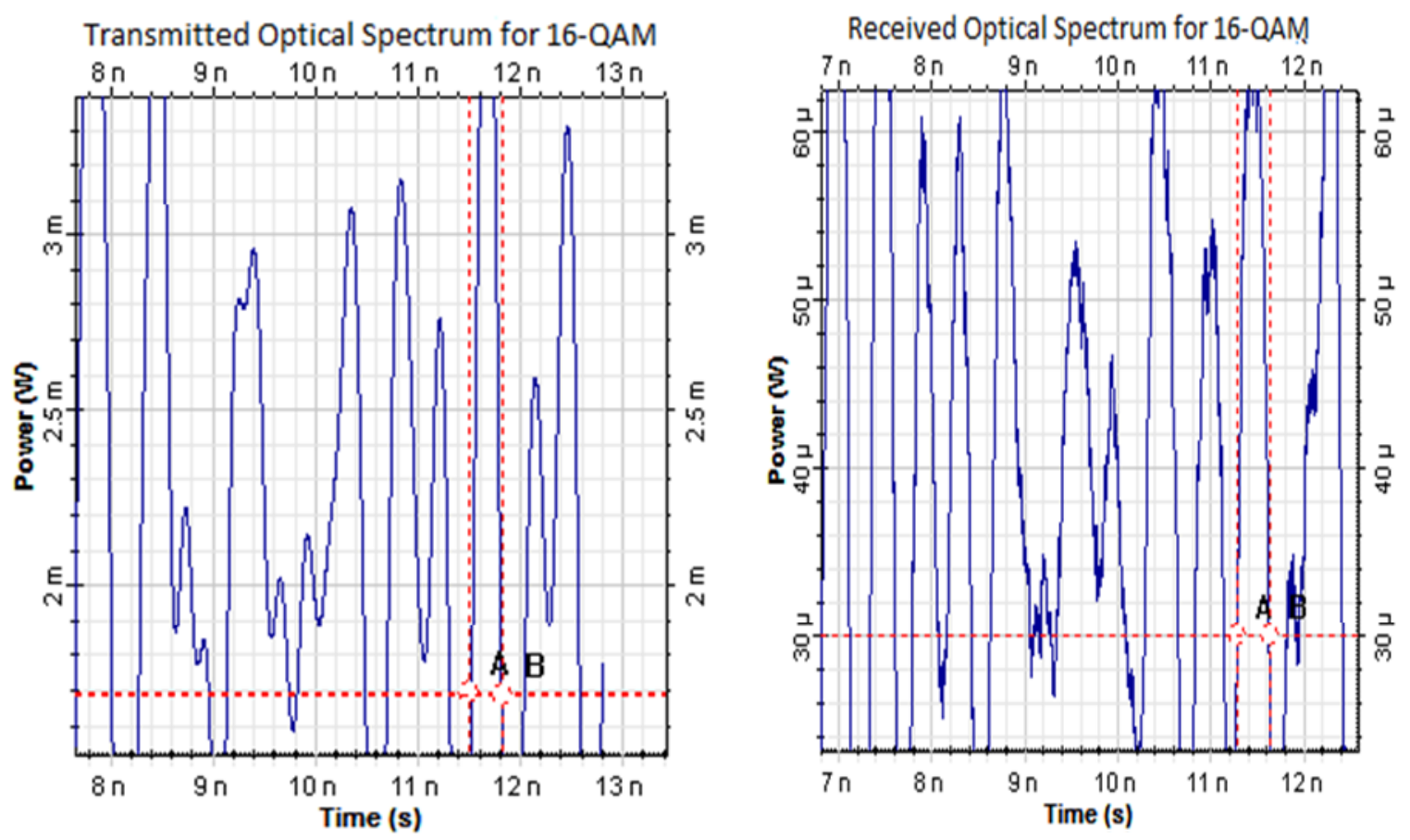

Figure 6. Transmitted and Received Optical Spectrum for 16-QAM

Likewise the transmitted and received optical spectra for 16-QAM (Figure 6) shows that the FWHM width of the transmitted pulse is $\mathrm{T}_{\mathrm{FWHM} \text { (trans) }}=0.30 \mathrm{~ns}=300 \mathrm{ps}$ and FWHM width of the received pulse is $\mathrm{T}_{\mathrm{FWHM}}$ (receive) $-0.35 \mathrm{~ns}=350 \mathrm{ps}$. So, from (eq.1) the RMS width of the transmitted pulse is $\mathrm{T}_{\mathrm{in}}=\frac{\mathrm{T}_{\mathrm{FWHM}(\text { trans) }}}{1.665} \mathrm{ps} \approx 180 \mathrm{ps}$. And from (eq.2) the RMS width of the received pulse is $\mathrm{T}_{\text {out }}=\frac{\mathrm{T}_{\mathrm{FWHM}} \text { (receive) }}{1.665}$ ps $\approx 210$ ps. Now from eq.3 the RMS spectral width of the transmitted optical pulse $(\Delta \lambda)=\frac{\lambda^{2} \sqrt{1+\mathrm{C}^{2}}}{2 \pi \mathrm{c} \text { in }}=0.0431 \mathrm{~nm}$. So, the RMS width of the fiber impulse response $\left(\mathrm{T}_{\mathrm{F}}\right)=\mathrm{L} . \mathrm{D}(\lambda) . \Delta \lambda=(50 \mathrm{~km}) .(17 \mathrm{ps} / \mathrm{nm}-\mathrm{km}) .(0.0431 \mathrm{~nm})=36.635 \mathrm{ps}$. Thus the RMS width of the pulse at the far end of the optical fiber is $\mathrm{T}_{\text {out }}=\sqrt{\mathrm{T}_{\mathrm{in}}{ }^{2}+\mathrm{T}_{\mathrm{F}}{ }^{2}}=\sqrt{(180)^{2}+(36.635)^{2}}$ $=184 \mathrm{ps}$.

For 64-QAM (Figure 7), $\mathrm{T}_{\mathrm{FWHM}(\text { trans })}=0.31 \mathrm{~ns}=310 \mathrm{ps}, \mathrm{T}_{\mathrm{FWHM}}($ receive $)=0.37 \mathrm{~ns}=370 \mathrm{ps}$. Thus $\mathrm{T}_{\mathrm{in}}=\frac{\mathrm{T}_{\mathrm{FWHM}(\text { trans })}}{1.665} \mathrm{ps} \approx 186 \mathrm{ps}$ and $\mathrm{T}_{\mathrm{out}}=\frac{\mathrm{T}_{\mathrm{FWHM}(\text { receive })}}{1.665} \mathrm{ps} \approx 222 \mathrm{ps}$. And $\Delta \lambda=\frac{\lambda^{2} \sqrt{1+\mathrm{C}^{2}}}{2 \pi \mathrm{c} \mathrm{T}_{\text {in }}}=0.0417$ $\mathrm{nm}, \mathrm{T}_{\mathrm{F}}=\mathrm{L} . \mathrm{D}(\lambda) . \Delta \lambda=(50 \mathrm{~km}) .(17 \mathrm{ps} / \mathrm{nm}-\mathrm{km}) .(0.0417 \mathrm{~nm})=35.45 \mathrm{ps}$. Thus the RMS width of the pulse for QAM 64 at the far end of the optical fiber is $\mathrm{T}_{\mathrm{out}}=\sqrt{\mathrm{T}_{\mathrm{in}}{ }^{2}+\mathrm{T}_{\mathrm{F}}{ }^{2}}=\sqrt{(186)^{2}+(35.45)^{2}}$ $=189$ ps. 
International Journal of Computer Networks \& Communications (IJCNC) Vol.4, No.1, January 2012
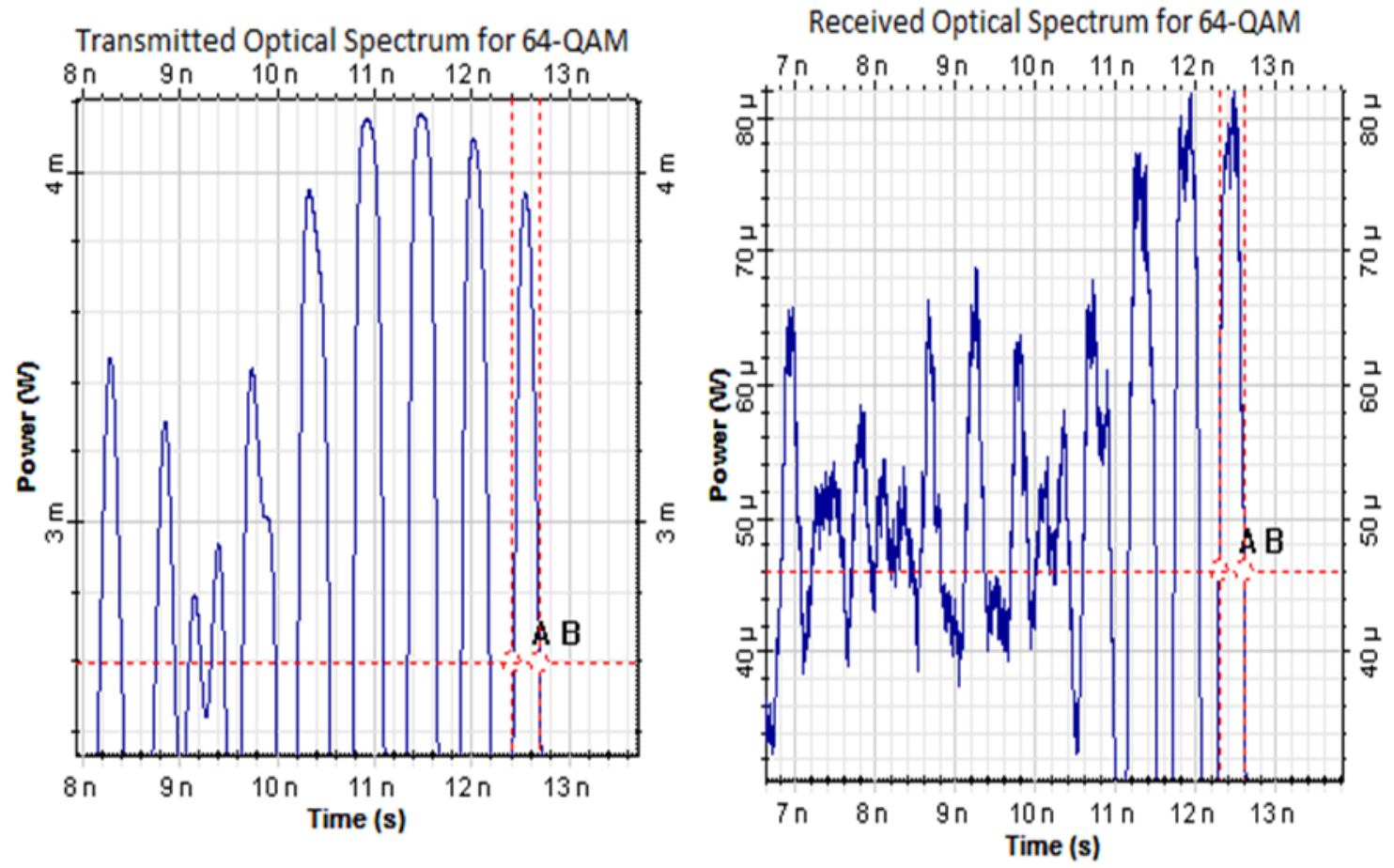

Figure 7. Transmitted and Received Optical Spectrum for 64-QAM.
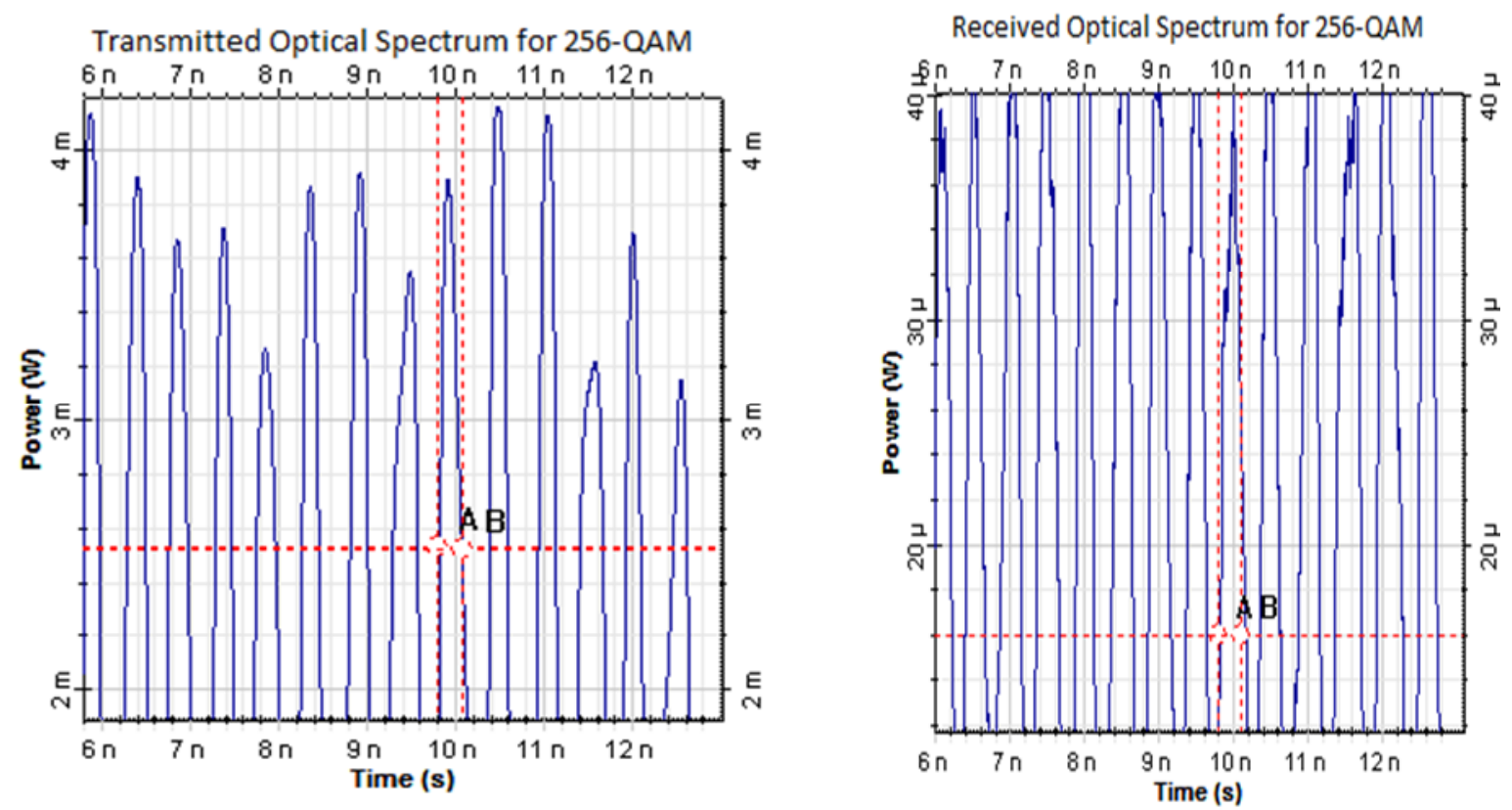

Figure 8.Transmitted and Received Optical Spectrum for 256-QAM 
International Journal of Computer Networks \& Communications (IJCNC) Vol.4, No.1, January 2012

And according to Figure 8,256-QAM has $\mathrm{T}_{\mathrm{FWHM}(\operatorname{trans})}=0.32 \mathrm{~ns}=320 \mathrm{ps}, \mathrm{T}_{\mathrm{FWHM}(\text { receive })}=0.39 \mathrm{~ns}$ $=390$ ps. Thus $\mathrm{T}_{\mathrm{in}}=\frac{\mathrm{T}_{\mathrm{FWHM}(\text { trans) }}}{1.665} \mathrm{ps} \approx 192 \mathrm{ps}$ and $\mathrm{T}_{\mathrm{out}}=\frac{\mathrm{T}_{\mathrm{FWHM}(\text { receive) }}}{1.665} \mathrm{ps} \approx 234$ ps. And $\Delta \lambda=$ $\frac{\lambda^{2} \sqrt{1+\mathrm{C}^{2}}}{2 \pi \mathrm{c} \mathrm{T}_{\mathrm{in}}}=0.0404 \mathrm{~nm}, \mathrm{~T}_{\mathrm{F}}=\mathrm{L} . \mathrm{D}(\lambda) . \Delta \lambda=(50 \mathrm{~km}) .(17 \mathrm{ps} / \mathrm{nm}-\mathrm{km}) .(0.0404 \mathrm{~nm})=34.34 \mathrm{ps}$. So, the calculated value of $\mathrm{T}_{\mathrm{out}}=\sqrt{\mathrm{T}_{\mathrm{in}}{ }^{2}+\mathrm{T}_{\mathrm{F}}{ }^{2}}=\sqrt{(192)^{2}+(34.34)^{2}}=195 \mathrm{ps}$.
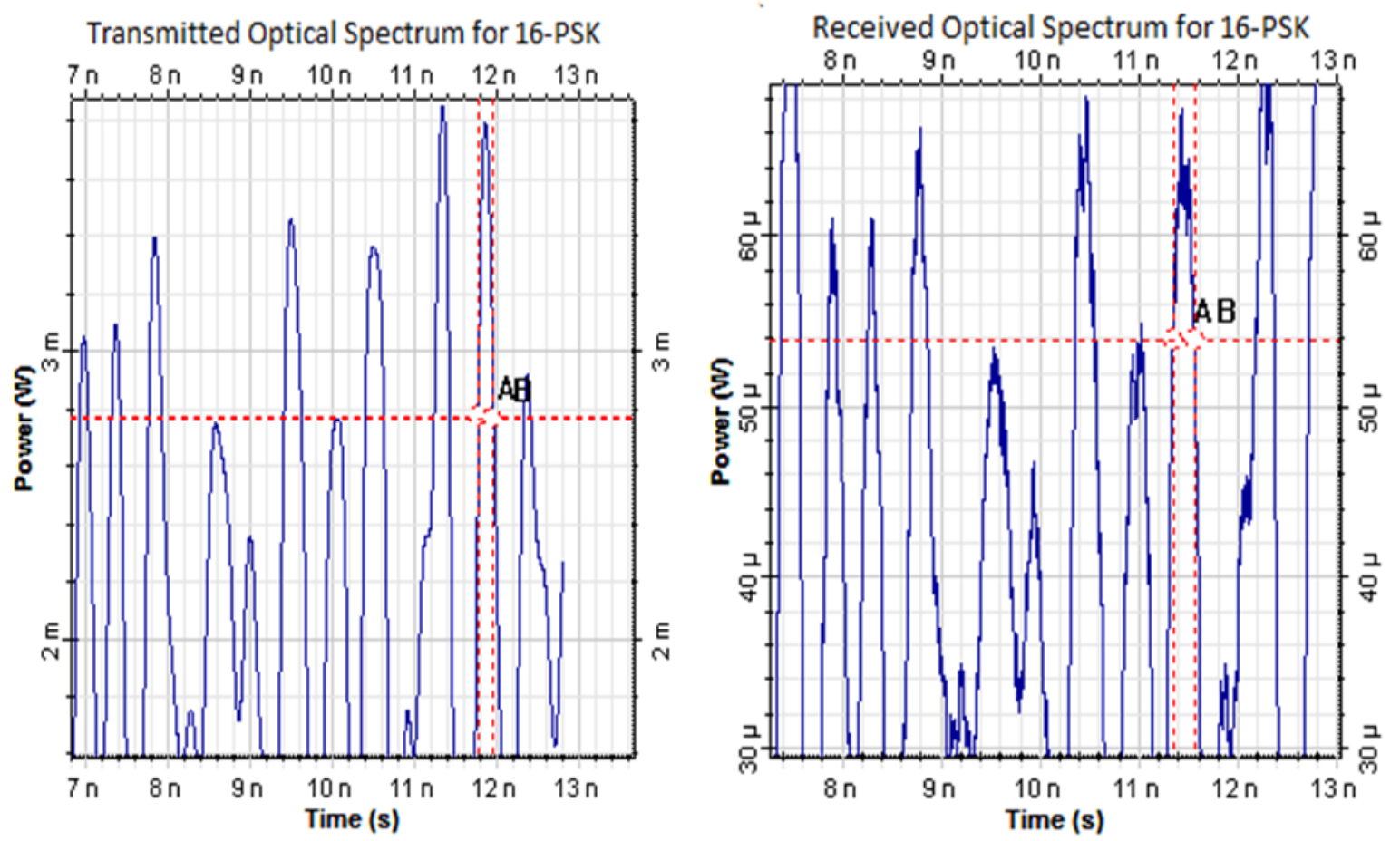

Figure 9.Transmitted and Received Optical Spectrum for 16-PSK

For 16-PSK (figure 9), $\mathrm{T}_{\mathrm{FWHM} \text { (trans) }}=0.21 \mathrm{~ns}=210 \mathrm{ps}, \mathrm{T}_{\mathrm{FWHM}(\text { receive) }}=0.27 \mathrm{~ns}=270 \mathrm{ps}$. Thus $\mathrm{T}_{\mathrm{in}}=\frac{\mathrm{T}_{\mathrm{FWHM}(\text { trans) }}}{1.665} \mathrm{ps} \approx 126 \mathrm{ps}$ and $\mathrm{T}_{\text {out }}=\frac{\mathrm{T}_{\mathrm{FWHM} \text { (receive) }}}{1.665} \mathrm{ps} \approx 162 \mathrm{ps}$. And $\Delta \lambda=\frac{\lambda^{2} \sqrt{1+\mathrm{C}^{2}}}{2 \pi \mathrm{c} \mathrm{T}_{\text {in }}}=0.0616$ $\mathrm{nm}, \mathrm{T}_{\mathrm{F}}=\mathrm{L} . \mathrm{D}(\lambda) . \Delta \lambda=(50 \mathrm{~km}) .(17 \mathrm{ps} / \mathrm{nm}-\mathrm{km}) .(0.0616 \mathrm{~nm})=52.36 \mathrm{ps}$. Thus the RMS width of the pulse for 16-PSK at the far end of the optical fiber is $\mathrm{T}_{\text {out }}=\sqrt{\mathrm{T}_{\mathrm{in}}{ }^{2}+\mathrm{T}_{\mathrm{F}}{ }^{2}}$ $=\sqrt{(126)^{2}+(52.36)^{2}}=136 \mathrm{ps}$. 

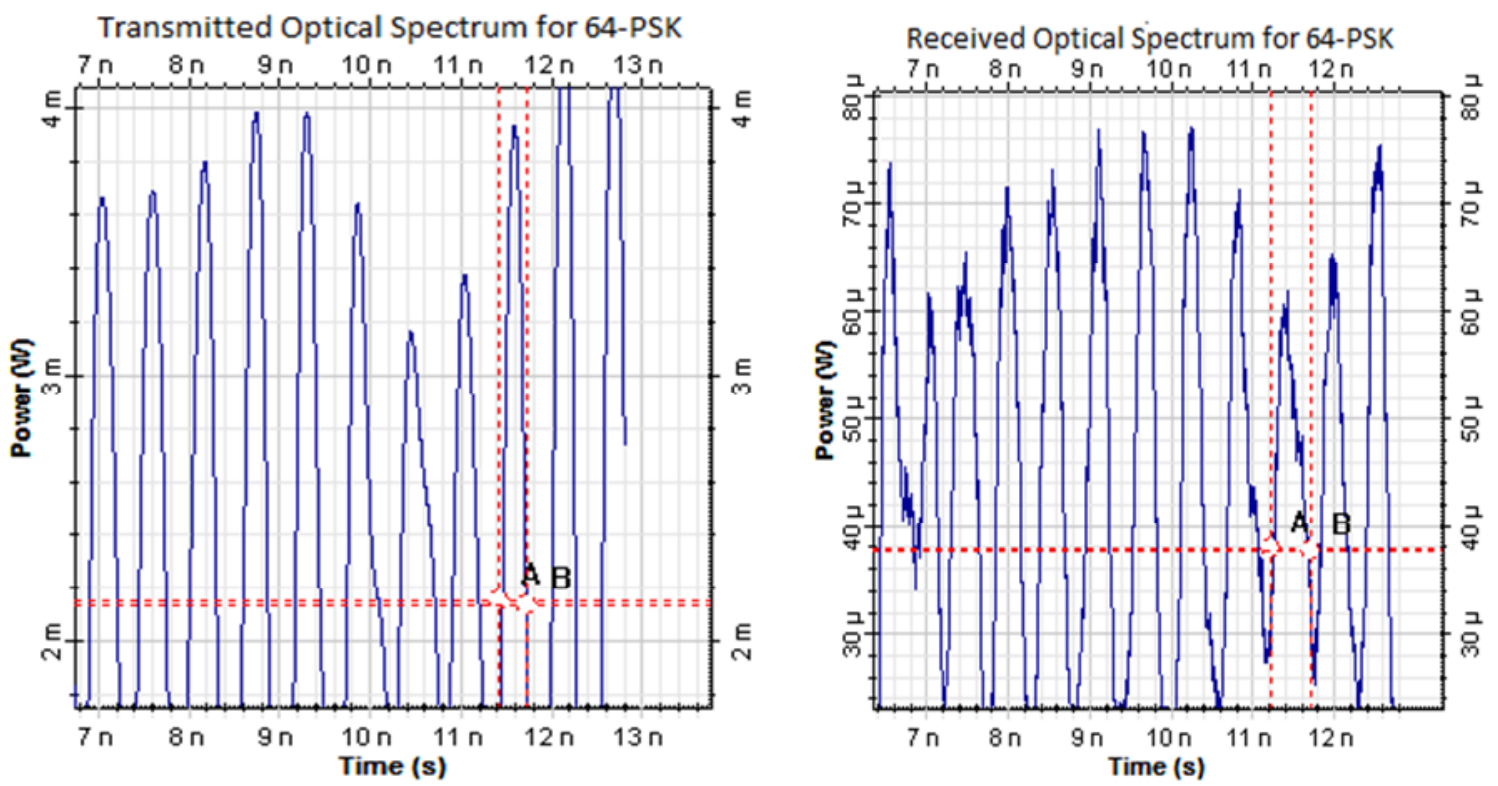

Figure 10.Transmitted and Received Optical Spectrum for 64-PSK

According to Figure10, 64-PSK has $\mathrm{T}_{\mathrm{FWHM}(\text { trans })}=0.35 \mathrm{~ns}=350 \mathrm{ps}, \mathrm{T}_{\mathrm{FWHM}(\text { receive })}=0.42 \mathrm{~ns}$ $=420 \mathrm{ps}$.
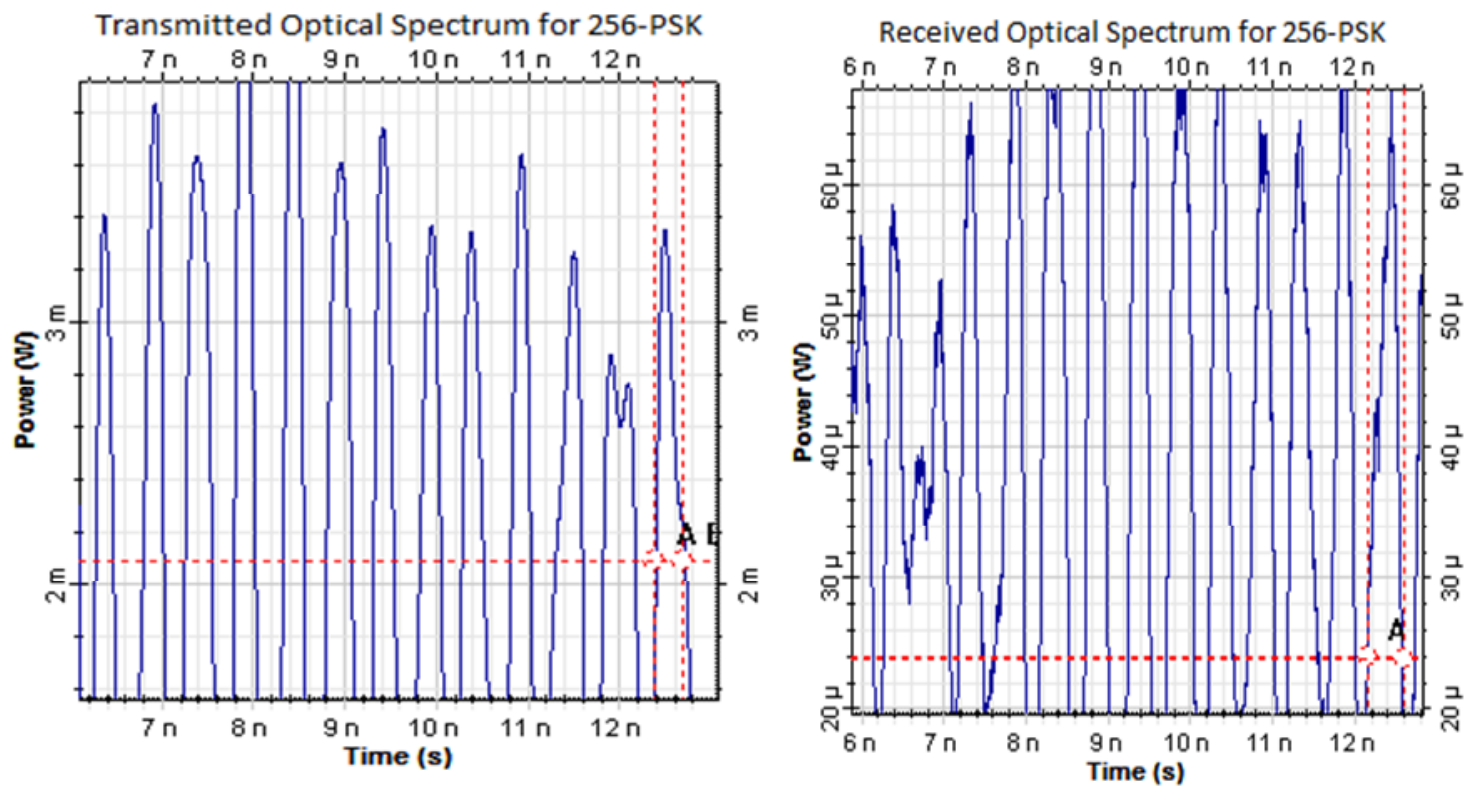

Figure 11. Transmitted and Received Optical Spectrum for 256-PSK 
Thus $\mathrm{T}_{\mathrm{in}}=\frac{\mathrm{T}_{\mathrm{FWHM} \text { (trans) }}}{1.665} \mathrm{ps} \approx 210 \mathrm{ps}$ and $\mathrm{T}_{\mathrm{out}}=\frac{\mathrm{T}_{\mathrm{FWHM}(\text { receive) }}}{1.665} \mathrm{ps} \approx 252 \mathrm{ps}$. And $\Delta \lambda=\frac{\lambda^{2} \sqrt{1+\mathrm{C}^{2}}}{2 \pi \mathrm{T}_{\mathrm{in}}}=$ $0.0369 \mathrm{~nm}, \mathrm{~T}_{\mathrm{F}}=\mathrm{L} . \mathrm{D}(\lambda) . \Delta \lambda=(50 \mathrm{~km}) .(17 \mathrm{ps} / \mathrm{nm}-\mathrm{km}) .(0.0369 \mathrm{~nm})=31.37 \mathrm{ps}$. So, the calculated value of $\mathrm{T}_{\mathrm{out}}=\sqrt{\mathrm{T}_{\mathrm{in}}{ }^{2}+\mathrm{T}_{\mathrm{F}}^{2}}=\sqrt{(210)^{2}+(31.37)^{2}}=213 \mathrm{ps}$.

And, finally Figure 11 for 256-PSK shows that, $\mathrm{T}_{\mathrm{FWHM}(\operatorname{trans})}=0.33 \mathrm{~ns}=330 \mathrm{ps}$, $\mathrm{T}_{\mathrm{FWHM}(\text { receive })}=0.41 \mathrm{~ns}=410$ ps. Thus $\mathrm{T}_{\mathrm{in}}=\frac{\mathrm{T}_{\mathrm{FWHM}(\text { trans })}}{1.665} \mathrm{ps} \approx 198 \mathrm{ps}$ and $\mathrm{T}_{\text {out }}=\frac{\mathrm{T}_{\mathrm{FWHM}(\text { receive })}}{1.665} \mathrm{ps}$ $\approx 246$ ps. And $\Delta \lambda=\frac{\lambda^{2} \sqrt{1+\mathrm{C}^{2}}}{2 \pi \mathrm{c} \mathrm{T}_{\mathrm{in}}}=0.0392 \mathrm{~nm}, \mathrm{~T}_{\mathrm{F}}=\mathrm{L} . \mathrm{D}(\lambda) . \Delta \lambda=(50 \mathrm{~km}) .(17 \mathrm{ps} / \mathrm{nm}-\mathrm{km}) .(0.0392$ $\mathrm{nm})=33.32 \mathrm{ps}$. Thus the RMS width of the pulse for 16-PSK at the far end of the optical fiber is $\mathrm{T}_{\text {out }}=\sqrt{\mathrm{T}_{\text {in }}{ }^{2}+\mathrm{T}_{\mathrm{F}}^{2}}=\sqrt{(198)^{2}+(33.32)^{2}}=201 \mathrm{ps}$.

In Figure 5 to Figure 11 we epitomized the transmitted and received optical pulse at the far end of the Optical fiber (at differenr ONU's) for different QAM and for different PSK modulation scheme through an Optical Time Domain Analyzer (OTDA). And we can see that by increasing the number of bits per symbol from 2 to 8 per symbol (for QPSK to 256-QAM or 256-PSK) we can increase the OFDM transmission rate with a certain amount of dispersion (that means the received pulsese gets wider than the transmitted one).

Table 1. Comparing dispersion factor for different modulation schemes

\begin{tabular}{|c|c|c|c|c|c|c|}
\hline \multirow{2}{*}{$\begin{array}{c}\text { M-QAM / } \\
\text { PSK } \\
\text { modulation }\end{array}$} & \multirow{2}{*}{$\begin{array}{c}\text { RMS width of } \\
\text { transmitted } \\
\text { pulse }\left(T_{i n}\right)\end{array}$} & \multicolumn{2}{|c|}{$\begin{array}{c}\text { RMS width of received } \\
\text { pulse }\left(T_{\text {out }}\right)\end{array}$} & \multicolumn{2}{|c|}{$\begin{array}{r}\text { Dispersion }= \\
T_{\text {out }}-T_{\text {in }}\end{array}$} & \multirow[t]{2}{*}{$\begin{array}{c}\text { Difference } \\
=M_{D}-C_{D}\end{array}$} \\
\hline & & $\begin{array}{l}\text { Calculated } \\
\text { value }\end{array}$ & $\begin{array}{l}\text { Measured } \\
\text { value }\end{array}$ & $\begin{array}{c}\text { Calculated } \\
\left(C_{D}\right)\end{array}$ & $\begin{array}{c}\text { Measured } \\
\left(M_{D}\right)\end{array}$ & \\
\hline QPSK & $132 \mathrm{ps}$ & $141 \mathrm{ps}$ & $150 \mathrm{ps}$ & $9 \mathrm{ps}$ & $18 \mathrm{ps}$ & $9 \mathrm{ps}$ \\
\hline 16-QAM & $180 \mathrm{ps}$ & $184 \mathrm{ps}$ & $210 \mathrm{ps}$ & $4 \mathrm{ps}$ & $30 \mathrm{ps}$ & $26 \mathrm{ps}$ \\
\hline 64-QAM & $186 \mathrm{ps}$ & $189 \mathrm{ps}$ & $222 \mathrm{ps}$ & $3 \mathrm{ps}$ & $36 \mathrm{ps}$ & $33 \mathrm{ps}$ \\
\hline 256-QAM & $192 \mathrm{ps}$ & $195 \mathrm{ps}$ & $234 \mathrm{ps}$ & $3 \mathrm{ps}$ & $42 \mathrm{ps}$ & $39 \mathrm{ps}$ \\
\hline 16-PSK & $126 \mathrm{ps}$ & $136 \mathrm{ps}$ & $162 \mathrm{ps}$ & $10 \mathrm{ps}$ & $36 \mathrm{ps}$ & $26 \mathrm{ps}$ \\
\hline 64-PSK & $210 \mathrm{ps}$ & $213 \mathrm{ps}$ & $252 \mathrm{ps}$ & $3 \mathrm{ps}$ & $42 \mathrm{ps}$ & $39 \mathrm{ps}$ \\
\hline 256-PSK & $198 \mathrm{ps}$ & $201 \mathrm{ps}$ & $246 \mathrm{ps}$ & $3 \mathrm{ps}$ & $48 \mathrm{ps}$ & $45 \mathrm{ps}$ \\
\hline
\end{tabular}

Here Table 1 shows the overall summary of the dispersion/ pulse broadening quantity at the far end of the optical fiber for different modulation schemes. From the table we can see that for QPSK the measured dispersion and the difference between the calculated and measured value is minimum but as we move on to higher order modulations (from 16-QAM up to 256-QAM or from 16-PSK up to 256-PSK) the dispersion increases significantly. And among all of the modulation QPSK is the best choice for our proposed model. 
International Journal of Computer Networks \& Communications (IJCNC) Vol.4, No.1, January 2012

\section{CONCLUSION}

In this paper we proposed a novel light-wave centralized passive optical network (PON) based on various modulation schemes and simulated throughafiber optic based simulation software called Optisystem. Previous research works related to PON derived bit error rate (BER) from the measured vector magnitude (EVM) [15] and compared the performance among different m-QAM modulation techniques but never showed the performance measurements for both PSK and QAM together based on dispersion factor with numerical analysis. But in our paper we considered and compared the dispersion through both numerical analysis and simulated results for both m-PSK and m-QAM.The symmetric OFDM-PON traffic $(2.5 \mathrm{~Gb} / \mathrm{s}$ for each ONU) is experimentally portrayed over $50 \mathrm{~km}$ single mode fiber followed by an additional 1:2 optical splitter. It's a simple OFDM based PON architecture that has provenits viability as a flexible, high-speed and cost-effective network and could be a potential choice for future PON systems since the data rate of the present PONs can be upgraded easily without significantly changing the network infrastructure .

\section{REFERENCES}

[1] L.G. Kazovsky, W.-T.Shaw, D. Gutierrez, N. Cheng, and S.-W.Wong, "Next-Generation Optical Access Network," J. Lightwave Technol. 25(11), 3428-3442 (2007).

[2] R. Davey, J. Kani, F. Bourgart, and K. McCammon, "Options for Future Optical Access Networks," IEEE Commun. Mag. 44(10), 50-56 (2006).

[3] Y. M. Lin, "Demonstration and design of high spectral efficiency 4Gb/s OFDM system inpassive optical networks", Proc. of OFC, 2007, Anaheim, USA, Paper OThD7.

[4] T. Duong, N. Genay, A. Pizzinat, B.Charbonnier, P. Chanclou, C. Kazmierski, "Low cost multi band-OFDM for remote modulation of colourless ONU in hybrid WDM/TDM-PON architecture," Proc. of ECOC, 2007, Berlin, Germany, Paper 5.4.2.

[5] S.Hara, Multicarrier Techniques for 4G Mobile Communications, Norwood, MA: Artech House, Incorporated, 2003.

[6]D.P. Shea, A. D. Ellis, D. B. Payne, R. P. Davey, and J. E. Mitchell "10 Gbit/s PON with 100 km reach and x1024 split," Proc. Of ECOC, Rimini, Italy, 2003, Paper We.P.147.

[7] G. Talli and P. D. Townsend, "Hybrid DWDM-TDM long-reach PON for next-generation optical access," J. Lightwave.Technol.24, 2827-2834 (2006).

[8] P. D. Townsend, G. Talli, C.W. Chow, E.M. MacHale, C. Antony, R. Davey, T. De Ridder, X. Z. Qiu, P.Ossieur, H.G. Krimmel, D. W. Smith, I. Lealman, A. Poustie, S. Randel, and H. Rohde, "Long reach Passive Optical Networks," IEEE LEOS Annual Meeting, Invited Paper, Florida, USA, 2007.

[9] D. Qian, J. Hu, J. Yu, P. N. Ji, L. Xu, T. Wang, M. Cvijetic, and T. Kusano, "Experimental demonstration of a novel OFDMA-based $10 \mathrm{~Gb} / \mathrm{s}$ PON architecture," in Proc. 2007 Eur. Conf. Opt. Commun. (ECOC), paper Mo 5.4.1. 
International Journal of Computer Networks \& Communications (IJCNC) Vol.4, No.1, January 2012

[10] W. Sheiegh and C. Athaudage."Coherent optical orthogonal frequency division multiplexing," Electron.Lett., vol. 42, pp. 587-589, 2006.

[11] F. Buchali and R. Dischler, "Optimized sensitivity direct-detection O-OFDM with multi level subcarrier modulation," presented at the Optical Fiber Communication Conference (OFC), San Diego, CA, 2008, paper OMU5.

[12] A. J. Lowery, L. Du, and J. Armstrong, "Orthogonal frequency division multiplexing for adaptive dispersion compensation in long haul WDM systems," presented at the Optical Fiber Communication Conference, Anaheim, CA., 2006, PDP 39.

[13] I. B. Djordjevic and B. Vasic, "Orthogonal frequency division multiplexing for high-speed optical transmission,” Optics Exp., vol. 14, pp. 3767-3775, 2006.

[14] J. M. Tang and K. A. Shore, "Maximizing the transmission performance of adaptively modulated optical OFDM signals in multimode-fiber links by optimizing analog-to-digital converters," J. Lightw.Technol., vol. 25, pp. 787-798, 2007.

[15] V. J. Urich, J. X. Qui, and F. Bucholtz, "Wide-band QAM-over-fiber Using Phase Modulation and Interferometric Demodulation,” IEEE Photon. Technol. Lett. 16(10), 2374-2376 (2004). 